\title{
$\begin{array}{ll}\text { Research Square } & \text { Preprints are preliminary reports that have not undergone peer review. } \\ \text { They should not be considered conclusive, used to inform clinical practice, }\end{array}$ or referenced by the media as validated information. \\ Treatment Repetitive Transcranial Magnetic Stimulation to Peripartum Depression: Systematic Review
}

\section{Hyunejune Lee}

Dongguk University

\section{Sungmin Kim}

Dongguk University

Ji Yean Kwon ( $\nabla$ jykwon@dgu.ac.kr)

Dongguk University https://orcid.org/0000-0002-9685-4531

\section{Research}

Keywords: Repetitive Transcranial Magnetic Stimulation, rTMS, peripartum depression, pregnancy

Posted Date: August 6th, 2020

DOl: https://doi.org/10.21203/rs.3.rs-52104/v1

License: @ (i) This work is licensed under a Creative Commons Attribution 4.0 International License. Read Full License 


\section{Abstract}

\section{Background}

Peripartum depression is a common disorder; it has very high potential hazards for both patients and their babies. Although peripartum depression therapy have typical options, antidepressant and electroconvulsive, these are not ensured concerning safe of fetus. Recently, repetitive Transcranial Magnetic Stimulation(rTMS) have been emerging as promising treatment for neuropathies including type of depression. Using magnetic field is expected to minimize effect on fetuses when used to treat peripartum depression. In this study, we are considering that whether the rTMS treatment is safe and effective for the mother and fetus in the treatment of peripartum depression.

\section{Purpose}

Performing systematical review, we confirm whether repetitive Transcranial Magnetic Stimulation is suitable treatment option for peripartum depression.

\section{Methods}

A systematic review followed the PRISMA guidelines and meta-analysis was performed by CMA3 software. We investigated literature prior to July 2020 using databases including MEDLINE, PsycINFO, EMBASE and Cochrane libraries, and conducted bias evaluation for suitable literature.

\section{Results}

rTMS have an effect on mitigating depression with $\mathrm{SMD}=1.394,95 \% \mathrm{Cl}: 0.944-1.843$ and. $37 \%$ of participants showed remission of the depression and $66 \%$ showed responded to repetitive Transcranial Magnetic Stimulation. A few side effect was reported and case of unusual side effect was two. However, we confirmed these are not related to TMS. There were no life-threatening side effects.

\section{Conclusions}

rTMS might be an attractive alternative treatment for pregnant women who are afraid of chemical effect to their child and life threatening side effect of ECT. Furthermore, rTMS could reduce socioeconomic costs of peripartum depression However, much research is needed to determine standardized protocol and evaluate effectiveness.

\section{Systematic review registration}

This systematic review was not registered.

\section{Background}

Peripartum depression (PPD) is commonly classified as occurrence of major depressive disorder (MDD) during pregnancy period and within 4 weeks after childbirth [1]. Even though PPD is common disorder that 10 $\sim 20 \%$ of pregnant women can experience [2], you will spend expensive life time cost of 75,728 pounds 
(US\$95.656) [3] if you have disease. PPD also threatens the health of pregnant women by causing an imbalance in hormones in the mother [4], potentially exposing her to alcohol and substance abuse [5], increasing risk of complications; maternal suicide [6] and PPD also lead serious hazard to the fetus by setting premature [7] and low weight [8]. Furthermore, it interferes with the formation of a stable attachment relationship with childhood, thus causing child self-control and cognitive function behavior [9].

Methods for treating PPD are mainly electroconvulsive therapy (ECT) and antidepressant [10]. Although both of them have proven their treatment effectiveness for PPD [11-14], those are being raised many problems about the safety of pregnant women and fetuses.

Antidepressants are a method to relieve depression by regulating the amount of neurotransmitters that related to emotion [15]. Neurotransmitters released from pre-synaptic neurons are transferred to the neurons after synapses; some of which are reabsorbed or decomposed by monoamine oxidase (MAO). Antidepressants interrupt reabsorption and MAO enzymes, making neurotransmitters less decomposed and finally reducing the degree of depression [16]. However, antidepressant could have a chemical effect on the fetus because components of antidepressant can pass through the placenta [17]. When the mother takes antidepressants during PPD, it causes 7-fold increase in the risk of spontaneously induced abortion [18, 19], premature birth and underweight of children [20], increase risk of fetal infections more than 3-fold [21], autism spectrum disorder of baby [22], increase risk of motor, speech and scholastic disorder [23], cardiac defects [24] and persistent pulmonary hypertension [25]. In addition, antidepressant components can be exposed to the fetus during the breastfeeding [26], which can increase monoamine levels and affect the functional maturity of the brain [27]. Side effects such as decreased feeding [28], colic, and irritability [29] have been reported.

Another treatment, ECT, is a method stimulating electrical shock in the brain to relieve depression. Electric shocks affecting neurons and chemicals in the brain lead to short and controlled seizures which have excellent effects in various neurological disorders [30]. However, treating ECT with pregnant women shows various adverse effects including vaginal bleeding and miscarriage [31], uterine contraction [32], abdominal pain [33], and Preeclampsia [34].

Since the risk of PPD is smaller than that of ECT and antidepressant [35, 36], those are used as a treatment for PPD, but considering the impact of each treatment on the fetus and baby, a study of safer treatments is needed.

Recently, with the recent development of brain stimulation research, many researchers are increasingly trying to use brain stimulation for various neurological treatment [37]. One of brain stimulation named repetitive Transcranial Magnetic Stimulation (rTMS) stimulates the brain's dorsolateral prefrontal Cortex (DLPFC) with magnetic fields to induce degeneration of neurons and activate neural system of brain to control nerve control materials to relieve depression [38]. Although studies have shown that rTMS is safe because of using magnetic fields that are harmless to the human [39] and is effective in a number of neurological diseases including depression [40-42], treatment using rTMS for PPD is reluctant due to the specificity of pregnancy [43-45].

In this regard, there were four systematic literature studies on how to treat TMS related PPD [46-49]. However, Gersimos N study was a comprehensive study of non-drug treatment available to pregnant patients and did 
not address the therapeutic effect or safety of rTMS [46]. A Ganho-Ávila study conducted a systematic literature review on patients with only postpartum depression [47]. Felipe's research was unreliable because the systematic review protocol was unclear and the number of study was only 3 [48]. J cole study did not quantitatively synthesize therapeutic effect size or safety [49].

In this study, we will evaluate the effect size and safety of rTMS on the mother's depression and whether it is a suitable method for the mother through systematic literature review and meta-analysis and reviewed the literature that received rTMS treatment from pregnancy to one year after childbirth, considering that the process of breastfeeding, etc. is affecting the growth of newborn babies [50-52].

\section{Data Source And Search Strategy}

We performed the search by using the literature published before June 2020 as keyword, using the EMBASE, MEDLINE, PsycINFO, and Cochrane Library database. Indication search term is not only peripartum depression but also antepartum depression, postpartum depression and pregnancy depression and the terms of treatment search were repeated transcranial magnetic stimulation, rTMS, transcranial magnetic stimulation and TMS. The detailed searching term and strategy are presented in Appendix 1. Generally, the literature used in meta-analysis is a randomized controlled trial(RCT) study, but non-randomized studies (NRS) which properly set up patients, intervention, comparison, outcome also can include in meta-analysis [53]. So in this study, NRS which were suitable through Cochrane algorithm were included. To minimize the omission of data and increase the reliability, two researchers independently reviewed the literature. But if the opinions of the researchers are different, the literature were reviewed together and reached an agreement. Following studies have been reported the major depressive disorder occurred months after childbirth, though DSM-5 states that the criteria for the peripartum depression is from gestation period to 1 month after delivery [50-52]. Therefore, we collected literature that treated rTMS within a year of birth, not 4 weeks, to consider not only the therapeutic effect of rTMS on the treatment of the peripartum depression, but also the effect on fetuses and newborns.

The criteria for exclusion are as follows: (1) experimental studies with animals, (2) when the depression rating scale was not Hamilton Depression Rating Scale, (3) studies were not published in English, (4) studies were not original or were grey literature, (5) when symptoms were baby blues and postpartum psychosis and (6) major depressive disorder did not occur from pregnancy to 1 year after childbirth.

The literature was selected according to the criteria set for all literature searched. After the screening process, the selected literature was extracted. The extracted data include basic information about literature, study characteristics to ensure that rTMS well designed for peripartum depression treatment and side effects, demographic and sociological characteristics to see whether proper patients screening has been performed, rTMS parameters known to affect the therapeutic effect [54] and the condition of a mother and newborn. The detailed are presented in Fig. 1.

Two evaluators independently reviewed the quality of the data and the risk of bias. RCT studies were examined using the Risk of bias 2 (ROB2) [55] and NRS were examined using the Risk of Bias Assessment tool for Nonrandomized Studies (ROBINS-I) [56]. Case reports and series were not ignored as a medical 
literature [57]. Therefore, we evaluating using Methodological quality tool [58]. The final judgment on the overall risk of bias was agreed between the two evaluators.

Data analysis was conducted using CMA3 statistical software. For therapeutic effects, two group pre-post data in RCT and one group pre-post data for NRS were analyzed and for safety, Event rates both RCT and NRS were analyzed. Effect size was confirmed by Standardized Mean Deviation (SMD) 95\% Cl. The final calculation results are shown in the Forest plot.

\section{Results}

\section{Search results}

The literature search was conducted in accordance with PRISMA FLOW, and a summary of the search results is presented in Fig. 2. The total number of studies found in each database was 215 . After excluding 101 studies due to duplication, 114 studies were left. Afterwards, 83 studies were excluded due to animal studies, non-original grey literature, non-English literature, and literature with unsuitable indications and treatments according to the inclusion and exclusion criteria. 31 documents were judged by the full text review whether they were suitable for our research purposes and finally, 11 literatures were suitable for identifying the effects and safety of rTMS on peripartum depression and detailed Excluded literature and the reasons are presented in Appendix 2. The original text was requested through the author's e-mail if only abstract was present. Finally, there were 11 studies suitable for qualitative synthesis and 5 studies suitable for quantitative synthesis.

\section{Characteristics of Selected Studies}

There were a total of 11 selected literature related to the efficacy and safety of rTMS for PPD, of which 2 RCT studies [59,60], 4 NRS [61-64], and 5 case studies [64-68]. The total number of participants are 100, 83 of whom received activee rTMS treatment. During pregnancy, 65 patients were treated with rTMS and most of them consisted of the second and third trimester of pregnancy. 17 patients were treated for postpartum depression and 2 patients were treated during pregnancy and after childbirth. The people included in the study were suffering from severe depression with HDRS scores of 17 or more point, two of which showed biopolar disorder. 20 participants were treated antidepressants $[61,63,66,69]$ along with rTMS, 6 participants were treated on psychotropic $[59,64]$ and 1 participant was treated on clonazepam for insomnia [62]. 
Table 1

Characteristics of subjects included studies

\begin{tabular}{|c|c|c|c|c|c|c|}
\hline Study & Study design & Subjects & Age & $\begin{array}{l}\text { Gestational } \\
\text { age }\end{array}$ & $\begin{array}{l}\text { Psychiatric } \\
\text { diagnosis }\end{array}$ & $\begin{array}{l}\text { Simultaneous } \\
\text { treatment }\end{array}$ \\
\hline \multirow{4}{*}{$\begin{array}{l}\text { D. R. Kim et al., } \\
2019 \text { [59] }\end{array}$} & \multirow{4}{*}{$\begin{array}{l}\text { Randomized } \\
\text { controlled trial }\end{array}$} & \multirow{2}{*}{$\begin{array}{l}\text { Active } \\
11\end{array}$} & \multirow{2}{*}{$\begin{array}{l}30.13 \\
\pm 5.78\end{array}$} & $22.19 \pm 7.11$ & \multirow[t]{4}{*}{ MDD } & \multirow[t]{4}{*}{ Free } \\
\hline & & & & (Weeks) & & \\
\hline & & \multirow{2}{*}{$\begin{array}{l}\text { Sham } \\
11\end{array}$} & \multirow{2}{*}{$\begin{array}{l}26.41 \\
\pm 5.11\end{array}$} & $25.62 \pm 7.61$ & & \\
\hline & & & & (Weeks) & & \\
\hline \multirow[t]{5}{*}{$\begin{array}{l}\text { Myczkowski et } \\
\text { al., } 2012 \text { [60] }\end{array}$} & \multirow{5}{*}{$\begin{array}{l}\text { Double-blind } \\
\text { Randomized } \\
\text { controlled trial }\end{array}$} & \multirow[t]{3}{*}{ Active 8} & \multirow[t]{3}{*}{$\begin{array}{l}29.63 \\
\pm 6.37\end{array}$} & $4.13 \pm 2.85$ & \multirow[t]{5}{*}{ MDD } & \multirow[t]{5}{*}{ Free } \\
\hline & & & & & & \\
\hline & & & & (Month) & & \\
\hline & & \multirow[t]{2}{*}{ Sham 6} & \multirow{2}{*}{$\begin{array}{l}26.67 \\
\pm 7.15\end{array}$} & $3.50 \pm 2.74$ & & \\
\hline & & & & (Month) & & \\
\hline \multirow[t]{2}{*}{$\begin{array}{l}\text { D. R. Kim et al., } \\
2011 \text { [61] }\end{array}$} & \multirow{2}{*}{$\begin{array}{l}\text { Non } \\
\text { Randomized } \\
\text { controlled trial }\end{array}$} & \multirow[t]{2}{*}{10} & \multirow[t]{2}{*}{$\begin{array}{l}31.2 \\
\pm 5.6\end{array}$} & $25.8 \pm 5.16$ & \multirow[t]{2}{*}{ MDD } & $\begin{array}{l}4 \text { patients } \\
\text { treated }\end{array}$ \\
\hline & & & & (weeks) & & $\begin{array}{l}\text { on } \\
\text { antidepressant }\end{array}$ \\
\hline \multirow[t]{2}{*}{$\begin{array}{l}\text { Hizli Sayar et } \\
\text { al., } 2014 \text { [63] }\end{array}$} & \multirow{2}{*}{$\begin{array}{l}\text { Non- } \\
\text { Randomized } \\
\text { controlled trial }\end{array}$} & \multirow[t]{2}{*}{29} & \multirow[t]{2}{*}{$\begin{array}{l}32.69 \\
\pm 3.69\end{array}$} & $14.26 \pm 8.25$ & \multirow[t]{2}{*}{ MDD } & $\begin{array}{l}12 \text { patients } \\
\text { treated }\end{array}$ \\
\hline & & & & & & $\begin{array}{l}\text { on } \\
\text { antidepressant }\end{array}$ \\
\hline \multirow[t]{3}{*}{$\begin{array}{l}\text { Garcia et al., } \\
2010 \text { [62] }\end{array}$} & \multirow{3}{*}{$\begin{array}{l}\text { Non- } \\
\text { Randomized } \\
\text { controlled trial }\end{array}$} & \multirow[t]{3}{*}{7} & \multirow[t]{3}{*}{$\begin{array}{l}34.11 \\
\pm 6.05\end{array}$} & After birth & \multirow[t]{3}{*}{ MDD } & \multirow[t]{3}{*}{ Free } \\
\hline & & & & 30 days to & & \\
\hline & & & & 1 year & & \\
\hline \multirow[t]{2}{*}{$\begin{array}{l}\text { Tarhan et al., } \\
2012 \text { [70] }\end{array}$} & $\begin{array}{l}\text { Non- } \\
\text { Randomized }\end{array}$ & \multirow[t]{2}{*}{7} & * & * & MDD & * \\
\hline & controlled trial & & & & & \\
\hline Zhang et al., & Case report & 1 & 28 & 14 & MDD & Free \\
\hline & & & & (weeks) & & \\
\hline $\begin{array}{l}\text { Tan et al., } 2008 \\
\text { [64] }\end{array}$ & Case report & 1 & 30 & $\begin{array}{l}\text { From } 0 \text { to } \\
\text { postpartum } \\
\text { period }\end{array}$ & MDD & Free \\
\hline $\begin{array}{l}\text { Ferra o et al., } \\
2018 \text { [66] }\end{array}$ & Case report & 3 (Left) & $\begin{array}{l}35.7 \\
\pm 2.05\end{array}$ & $6.67 \pm 3.06$ & MDD & $\begin{array}{l}2 \text { patients } \\
\text { treated }\end{array}$ \\
\hline & & & & & & $\begin{array}{l}\text { on } \\
\text { antidepressant }\end{array}$ \\
\hline
\end{tabular}




\begin{tabular}{|c|c|c|c|c|c|c|}
\hline Study & Study design & Subjects & Age & $\begin{array}{l}\text { Gestational } \\
\text { age }\end{array}$ & $\begin{array}{l}\text { Psychiatric } \\
\text { diagnosis }\end{array}$ & $\begin{array}{l}\text { Simultaneous } \\
\text { treatment }\end{array}$ \\
\hline & & 1 (Right) & 36 & $\begin{array}{l}8 \\
\text { (weeks) }\end{array}$ & & $\begin{array}{l}1 \text { patients } \\
\text { treated } \\
\text { on } \\
\text { antidepressant }\end{array}$ \\
\hline $\begin{array}{l}\text { Cohen et al., } \\
2008 \text { [67] }\end{array}$ & Case report & 1 & 30 & $\begin{array}{l}20 \\
\text { (weeks) }\end{array}$ & MDD & Free \\
\hline \multirow[t]{2}{*}{$\begin{array}{l}\text { Monika Klírová } \\
\text { et al [68] }\end{array}$} & \multirow[t]{2}{*}{ Case report } & 1 (Left) & 30 & $\begin{array}{l}16 \\
\text { (weeks) }\end{array}$ & MDD & $\begin{array}{l}\text { Treated on } \\
\text { antidepressant }\end{array}$ \\
\hline & & 1 (Right) & 30 & $\begin{array}{l}31 \\
\text { (weeks) }\end{array}$ & MDD & $\begin{array}{l}\text { Treated on } \\
\text { antidepressant }\end{array}$ \\
\hline
\end{tabular}

Because protocols for rTMS treatment for peripartum depression have not yet been established, protocols for each study have all been different. 22 patients were stimulated the right DLPFC [59, 61, 66, 67], 79 patients were stimulated the left DLPFC [60,62-66, 70], and Burton et al [69] attempted to treat using combination of right and left DLPFC stimulation, and Ferra o et al [66] assigned different protocol and stimulation sites depending on the symptom of patients. The right DLPFC was stimulated using $1 \mathrm{~Hz}$ and the left DLPFC was treated with relatively high frequencies of 1 to $25 \mathrm{~Hz}$. In the process of treatment, some rTMS parameters such as number of pulses, and number of session were different in all studies, but researcher consider interval time and stimulus duration to minimize adverse event like a seizure. 
Table 2

Characteristics of Treatment included studies

\begin{tabular}{|c|c|c|c|c|c|c|}
\hline Study & $\begin{array}{l}\text { Motor } \\
\text { threshold }\end{array}$ & $\begin{array}{l}\text { Site of } \\
\text { Stimulation }\end{array}$ & Frequency & $\begin{array}{l}\text { Number of } \\
\text { pulses }\end{array}$ & $\begin{array}{l}\text { Inter- } \\
\text { event } \\
\text { interval }\end{array}$ & $\begin{array}{l}\text { Number of } \\
\text { Session }\end{array}$ \\
\hline $\begin{array}{l}\text { D. R. Kim et al., } 2019 \\
\text { [59] }\end{array}$ & $100 \%$ & $\begin{array}{l}\text { Right } \\
\text { DLPFC* }\end{array}$ & $1-\mathrm{Hz}$ & 900 & $\begin{array}{l}60 \mathrm{~s} \text { on } \\
60 \mathrm{~s} \\
\text { off }\end{array}$ & 20 \\
\hline $\begin{array}{l}\text { Myczkowski et al., } \\
2012 \text { [60] }\end{array}$ & $120 \%$ & Left DLPFC & $5-\mathrm{Hz}$ & 1250 & $\begin{array}{l}10 \mathrm{~s} \text { on } \\
20 \mathrm{~s} \\
\text { off }\end{array}$ & 25 \\
\hline $\begin{array}{l}\text { D. R. Kim et al., } 2011 \\
\text { [61] }\end{array}$ & $100 \%$ & $\begin{array}{l}\text { Right } \\
\text { DLPFC }\end{array}$ & $1-\mathrm{Hz}$ & 300 & $\begin{array}{l}60 \mathrm{~s} \text { on } \\
60 \mathrm{~s} \\
\text { off }\end{array}$ & 20 \\
\hline $\begin{array}{l}\text { Hizli Sayar et al., } 2014 \\
\text { [63] }\end{array}$ & $100 \%$ & Left DLPFC & $25-\mathrm{Hz}$ & 1000 & $\begin{array}{l}2 \mathrm{~s} \text { on } \\
30 \mathrm{~s} \\
\text { off }\end{array}$ & 18 \\
\hline Garcia et al., 2010 [62] & $120 \%$ & Left DLPFC & $10-\mathrm{Hz}$ & 150 & $\begin{array}{l}4 \mathrm{~s} \text { on } \\
26 \mathrm{~s} \\
\text { off }\end{array}$ & 20 \\
\hline $\begin{array}{l}\text { Tarhan et al., } 2012 \\
\text { [70] }\end{array}$ & $100 \%$ & Left DLPFC & $25-\mathrm{Hz}$ & 1000 & $\begin{array}{l}2 \mathrm{~s} \text { on } \\
30 \mathrm{~s} \\
\text { off }\end{array}$ & 18 \\
\hline Zhang et al., 2010 [65] & $90 \%$ & Left DLPFC & $1-\mathrm{Hz}$ & 1200 & $\begin{array}{l}20 \mathrm{~s} \\
\text { off }\end{array}$ & 42 \\
\hline Tan et al., 2008 [64] & $110 \%$ & Left DLPFC & $25-\mathrm{Hz}$ & 1000 & $\begin{array}{l}2 \mathrm{~s} \text { on } \\
28 \mathrm{~s} \\
\text { off }\end{array}$ & 77 \\
\hline $\begin{array}{l}\text { Ferra o et al., } 2018 \\
\text { [66] }\end{array}$ & $120 \%$ & $\begin{array}{l}\text { Left DLPFC } \\
\text { Right } \\
\text { DLPRC }\end{array}$ & $\begin{array}{l}10-\mathrm{Hz} \\
1-\mathrm{Hz}\end{array}$ & $\begin{array}{l}3000 \\
1800\end{array}$ & * & $\begin{array}{l}42.67 \\
20\end{array}$ \\
\hline Cohen et al., 2008 [67] & $110 \%$ & $\begin{array}{l}\text { Right } \\
\text { DLPFC }\end{array}$ & $1-\mathrm{Hz}$ & 1600 & * & 1 \\
\hline $\begin{array}{l}\text { Monika Klírová et al } \\
\text { [68] }\end{array}$ & $100 \%$ & Left DLPFC & $20-\mathrm{Hz}$ & 2000 & $\begin{array}{l}2 \mathrm{~s} \text { on } \\
30 \mathrm{~s} \\
\text { off }\end{array}$ & 15 \\
\hline
\end{tabular}

* DLPFC: Dorsolateral prefrontal cortex 


\begin{tabular}{|c|c|c|c|c|c|c|}
\hline Study & $\begin{array}{l}\text { Motor } \\
\text { threshold }\end{array}$ & $\begin{array}{l}\text { Site of } \\
\text { Stimulation }\end{array}$ & Frequency & $\begin{array}{l}\text { Number of } \\
\text { pulses }\end{array}$ & $\begin{array}{l}\text { Inter- } \\
\text { event } \\
\text { interval }\end{array}$ & $\begin{array}{l}\text { Number of } \\
\text { Session }\end{array}$ \\
\hline & & $\begin{array}{l}\text { Right } \\
\text { DLPRC }\end{array}$ & $1-\mathrm{Hz}$ & 300 & $60 \mathrm{~s}$ on & 15 \\
\hline & & & & & $\begin{array}{l}60 \mathrm{~s} \\
\text { off }\end{array}$ & \\
\hline
\end{tabular}

The average improvement in depression showed a decrease rate of $59 \%$ for 76 patients, except for a study by Tarhan et al [70], which did not disclose specific HDRS scores of patients. 37\% participants showed remission of the depression (HDRS-17 $\leq 8$, HDRS- $21 \leq 7$, HDRS- $24 \leq 8$ ) and $66 \%$ showed responded to rTMS (HDRS score reduced more than $50 \%$ ). Among the two random clinical trial studies, D. R. Kim et al [67] showed $45.45 \%$ response rate for the control group, while response rate of the experimental group is $81 \%(p=0.088)$ and remission rate was $18.18 \%$ for the control group whereas remission rate of the experimental group is $27.25 \%(p=0.613)$, showing a high therapeutic effect. Additionally, another Myczkowski et al [60] showed 7\% decrease of HDRS scores in the placebo group, but in the experimetal group, they showed a more than $30 \%$ deccrease rate $(p=0.020)$, similar to antidepressants. In NRS, the response rate of the 56 participants was $33 \%$ and the mission rate was 59\%. In Garcia et al., 2010 [62], HDRS scores of all participants fall below eight and without 1 participants, all of them experienced their HDRS scores drop by more than $50 \%$ and other NRS also revealed significant clinical results. In the case study, nine participants responded (rating scale reduction rate $\geq 50 \%$ ). 
Table 3

Characteristics of result included studies

\begin{tabular}{|c|c|c|c|c|c|c|c|}
\hline Study & Instrument & $\begin{array}{l}\text { Pre- } \\
\text { TMS }\end{array}$ & $\begin{array}{l}\text { Post- } \\
\text { TMS }\end{array}$ & Remission & Response & $\begin{array}{l}\text { Side effect } \\
\text { (mother) }\end{array}$ & Infants \\
\hline \multirow{2}{*}{$\begin{array}{l}\text { D. R. Kim et } \\
\text { al., } 2019 \\
\text { [59] }\end{array}$} & \multirow[t]{2}{*}{ HDRS-17 } & $\begin{array}{l}23.18 \\
\pm 3.54\end{array}$ & $\begin{array}{l}9.27 \\
\pm 6.05\end{array}$ & 3 & 9 & \multirow{2}{*}{$\begin{array}{l}1 \text { Patients } \\
\text { had } \\
\text { headache }\end{array}$} & $\begin{array}{l}3 \text { pre term } \\
\text { births }\end{array}$ \\
\hline & & $\begin{array}{l}22.27 \\
\pm 2.65\end{array}$ & $\begin{array}{l}13.18 \\
\pm 8.00\end{array}$ & 2 & 5 & & $\begin{array}{l}1 \text { shoulder } \\
\text { dystocia }\end{array}$ \\
\hline \multirow{2}{*}{$\begin{array}{l}\text { Myczkowski } \\
\text { et al., } 2012 \\
\text { [60] }\end{array}$} & \multirow[t]{2}{*}{ HDRS-17 } & $\begin{array}{l}29.13 \\
\pm 5.64\end{array}$ & $\begin{array}{l}18.50 \\
\pm 9.83\end{array}$ & \multirow[t]{2}{*}{ * } & \multirow[t]{2}{*}{ * } & \multirow{2}{*}{$\begin{array}{l}2 \text { Patients } \\
\text { had mild } \\
\text { headache }\end{array}$} & * \\
\hline & & $\begin{array}{l}26.67 \\
\pm 5.68\end{array}$ & $\begin{array}{l}24.83 \\
\pm 7.60\end{array}$ & & & & \\
\hline \multirow[t]{2}{*}{$\begin{array}{l}\text { D. R. Kim et } \\
\text { al., } 2011 \\
\text { [61] }\end{array}$} & \multirow[t]{2}{*}{ HDRS-17 } & \multirow[t]{2}{*}{$\begin{array}{l}24.4 \\
\pm 5.6\end{array}$} & \multirow[t]{2}{*}{$\begin{array}{l}9.7 \pm \\
6.1\end{array}$} & \multirow[t]{2}{*}{3} & \multirow[t]{2}{*}{7} & $\begin{array}{l}4 \text { Patients } \\
\text { had mild } \\
\text { headache. }\end{array}$ & \multirow[t]{2}{*}{$\begin{array}{l}\text { All infants } \\
\text { were well- } \\
\text { baby nursery }\end{array}$} \\
\hline & & & & & & $\begin{array}{l}1 \text { patients } \\
\text { had an } \\
\text { episode of } \\
\text { supine } \\
\text { hypotension }\end{array}$ & \\
\hline \multirow[t]{2}{*}{$\begin{array}{l}\text { Hizli Sayar } \\
\text { et al., } 2014 \\
\text { [63] }\end{array}$} & \multirow[t]{2}{*}{ HDRS-17 } & \multirow[t]{2}{*}{$\begin{array}{l}26.67 \\
\pm 5.58\end{array}$} & \multirow[t]{2}{*}{$\begin{array}{l}13.03 \\
\pm 6.93\end{array}$} & \multirow[t]{2}{*}{6} & \multirow[t]{2}{*}{12} & \multirow[t]{2}{*}{ None } & $\begin{array}{l}\text { None of baby } \\
\text { showed any }\end{array}$ \\
\hline & & & & & & & Abnormalities. \\
\hline $\begin{array}{l}\text { Garcia et al., } \\
2010 \text { [62] }\end{array}$ & HDRS-24 & $\begin{array}{l}22.67 \\
\pm 6.44\end{array}$ & $\begin{array}{l}2.14 \\
\pm 3.19\end{array}$ & 8 & 9 & $\begin{array}{l}\text { Headache, } \\
\text { site pain }\end{array}$ & * \\
\hline $\begin{array}{l}\text { Tarhan et } \\
\text { al., } 2012 \\
{[70]}\end{array}$ & HDRS-17 & * & * & 2 & 5 & None & $\begin{array}{l}\text { All gave } \\
\text { healthy } \\
\text { babies }\end{array}$ \\
\hline $\begin{array}{l}\text { Zhang et al., } \\
2010[65]\end{array}$ & HDRS-24 & 35 & 8 & 1 & 1 & None & Healthy boy \\
\hline $\begin{array}{l}\text { Tan et al., } \\
2008 \text { [64] }\end{array}$ & HDRS-17 & 38 & 4 & 1 & 1 & None & $\begin{array}{l}\text { No diagnosis } \\
\text { of disease }\end{array}$ \\
\hline \multirow[t]{2}{*}{$\begin{array}{l}\text { Ferra o et } \\
\text { al., 2018 } \\
\text { [66] }\end{array}$} & \multirow[t]{2}{*}{ HDRS-21 } & $\begin{array}{l}24.33 \\
\pm 5.24\end{array}$ & $\begin{array}{l}7.33 \\
\pm 4.03\end{array}$ & 2 & 3 & $\begin{array}{l}2 \text { patients } \\
\text { had } \\
\text { discomfort } \\
\text { at the } \\
\text { application } \\
\text { site. }\end{array}$ & $\begin{array}{l}\text { Twins were } \\
\text { preterm }\end{array}$ \\
\hline & & 12 & 6 & 1 & 1 & $\begin{array}{l}\text { discomfort } \\
\text { at the } \\
\text { application } \\
\text { site and } \\
\text { sore throat }\end{array}$ & \\
\hline
\end{tabular}




\begin{tabular}{|llllllll|}
\hline Study & Instrument & $\begin{array}{l}\text { Pre } \\
\text { TMS }\end{array}$ & $\begin{array}{l}\text { Post- } \\
\text { TMS }\end{array}$ & Remission & Response & $\begin{array}{l}\text { Side effect } \\
\text { (mother) }\end{array}$ & Infants \\
\hline $\begin{array}{l}\text { Cohen et al., } \\
2008 \text { [67] }\end{array}$ & HDRS-17 & 18 & 6 & 1 & 1 & $*$ & $\begin{array}{l}\text { The infant } \\
\text { had a normal } \\
\text { neurologic } \\
\text { development }\end{array}$ \\
$\begin{array}{l}\text { Monika } \\
\text { Klírová et } \\
\text { al.,2008 } \\
\text { [68] }\end{array}$ & MADRS & 33 & 2 & $*$ & $*$ & None & Healthy baby \\
\cline { 2 - 5 } & BDI & 29 & 12 & $*$ & $*$ & & \\
\hline
\end{tabular}

\section{Meta-analysis}

\section{Therapeutic effect}

All of the included studies used HDRS to identify degree of depression. The correlation coefficient was 0.5 [71] and because heterogeneity was $p<0.001, I^{2}=71.933$ the random effects model was applied [72]. rTMS have an effect on mitigating depression with $\mathrm{SMD}=1.806,95 \% \mathrm{Cl}: 0.920-2.692$ and the difference was statistically significant. $(Z=6.079, p<0.01)[73]$.

Abbreviations: BAI: Beck Anxiety Inventory; BDI: Beck depression Inventory; CGI-S: Clinical Global impression scale; EPDS: Edinburgh Postnatal Depression Scale; HDRS: Hamilton Depression Rating Scale; GAS, Global Assessment Scale; SF-36-V and SF-36-MH: 36-item Quality of Life Health Survey, Vitality and Mental Health scores; IDS-SR: Inventory of Depressive Symptomatology-Self-Report.

Figure 3. Forest plot of therapeutic effect

\section{Side effect}

The rate of occurrence of all side effects from the included studies was determined. The heterogeneity of the studies was $p=0.112, I^{2}=46.631$ so fixed effect model was applied [72]. The probability of side effects was small (event rate $=0.346, Z=-2.696, p=0.007$ ) [73].

Figure 4. Forest plot of side effect

\section{Sensitivity analysis}

Except for Garcia's study, which was too high therapeutic effect compared to other studies, the rTMS

Of SMD $=1.074(95 \% \mathrm{Cl}: 0.689-1.459, Z=5.468, P<0.001)$ showed significant therapeutic effect for PPD (Figure5).

Abbreviations: BAI: Beck Anxiety Inventory; BDI: Beck depression Inventory; CGI-S: Clinical Global 
impression scale; EPDS: Edinburgh Postnatal Depression Scale; HDRS: Hamilton Depression

Rating Scale; GAS, Global Assessment Scale; SF-36-V and SF-36-MH: 36-item Quality of Life

Health Survey, Vitality and Mental Health scores.

Figure 5. Forest plot of therapeutic effect without Garcia study

\section{Quality of the included studies}

According to experimental design, RCT was evaluated ROB2, NRS was ROBIN-I, case study was

Methodological quality tool and the detailed domain for the risk of bias assessment is presented in Appendix 3. Figure 7 is funnel plot for the Treatment effect of rTMS in treatment of PPD. The occurrence of asymmetric can be caused by publication bias or other causes.

(A) RCT risk of bias graph; (B) NRS risk of bias graph; (C) case study risk of bias graph

Figure 6. risk of bias graph

\section{Discussion}

Mothers are reluctant to treat antidepressants because they are concerned about the disadvantages of their own side effects, as well as the disadvantages to the fetus [74, 75], and in case of electroconvulsive therapy, only $1.2 \%$ of them accept them, and the majority are very negative because ECT has anesthesia process, and people worried about side effects such as post-treatment amnesia [76]. The population of this survey is public and if the population is limited to mothers, it will show lower acceptability. rTMS was also not well-received in the survey because it was not widely known as a recently re-examined treatment method, but after hearing the explanation of the treatment method, the acceptance rate of the mother for rTMS was significantly improved [77], as clinicians generally present the treatment effect while delivering knowledge of the treatment, so the acceptability of the mother acceptance of rTMS is positive.

The size of Therapeutic effect was SMD = 1.394 (95\% Cl: 0.944-1.843, Z = 6.079, p < 0.01) which was significant for treating depression [73]. Except for Garcia study [62] which is expected reporting bias because of selection report, $S M D=1.074(95 \% \mathrm{Cl}: 0.689-1.459, Z=5.468, p<0.001)$ which is meaningful result. The literature not included in the meta-analysis and excluded literature because those are not suitable selection criteria also supprot the therapeutic effect of rTMS for PPD [64, 66-70, 78-82]. In a studies included systematic review, $36 \%$ of the patients with PPD scored the same as the normal person and $66 \%$ saw their depression rating scale decrease by more than $50 \%$. In adddtion, Brock G study showed that 14 out of 19 patients reduced their Edinburgh Postnatal Depression Scale (EPDS) below 8 [80] and Ozmut study also showed that 8 out of 15 patients reduced their EPDS scores by more than $50 \%$. [79]. Other case-reporting [81, 82] also succeeded in improving patients with PPD using rTMS. Although parameters that can affect therapeutic effects such as stimulation site, frequency, and interval time are still being studied, thare are not much research data, we have been able to confirm that there is therapeutic effect without relying on multiple parameter settings on the literature collected, and if the protocol becomes more sophisticated, we will have a higher therapetic effect. 
Event rate $=0.346$ for side effects, which is statistically small but affected [73]. However, the side effects of rTMS treatment on mothers were minor, such as headaches, discomfort and pain in the stimulation area, and these side effects disapeeared at the end of the treatment process. Even this was reported similarly in RCT and is seen as a common side effect of TMS devices, not as a side effect in treating PPD. Supine hypotension was unexpected event [61] but a disease caused by a posture problem during treatment and was able to prevent supine hypotension through postural correction [83]. In case of antidepressants, side effects are commonly known as dizziness, hand tremors, cold sweats, lethargy and anxiety [84]. These side effect are constantly experienced in daily life and it can have a huge impact on pregnant women and mothers who need to take care of their infants [85]. In addition, $2.5 \%$ of mothers who suffer from treatment resistant depression and these have to choose a different treatment method [86]. Another theratment ECT was much serious. A direct and indirect study of fetal effects in mothers who was given ECT showed fatal side effects on fetuses and mothers including uterine contraction and vaginal bleeding, and a $7.1 \%$ of fetal mortality rate [13]. Compared to these two treatments and based on all the research we've done so far, The side effcts of on motheres do not affect their daily lives and are safe.

All children born from mothers with rTMS treatmnet were born healthy. And In one RCT study in which the child's health condition was determined by appearance-pulse-grimace-activity-respiration scores, the difference between the two group was not significant [experimental group 8.36(1.50), control group 8.73(0.90) $p=0.501][61]$.

There were five premature births and brachial flexus injury related to fetuses. Five percent of the participans in the study experienced premature birth, but two have already shown signs of premature birth risk in a biomedical test and the average rate of women experiencing premature births worldwide is 9.1 to $13.4 \%$ [87], it is unlikely that the causal relationship that rTMS treatment causes premature births will be established and further research is required. It was confirmed that brachial flexus injury was the only side effect that occurred in newborns, including premature births, and that it was not associated with rTMS treatment [59]. There were no actual side effects in the infant. Hizil Sayer performed following study that checked child of mother treated rTMS and reported that the exposure of Rtms during pregnancy did not affect the cognitive or motor development results of the child [88]. Although the results are fully reliable due to the lack of research, the magnetic field affecting fetal development is the lung and immune system [89] and it is also unlikely that rTMS will have a negative impact on fetal development and growth, given that magnetic is associated with diseases such as asthma at frequencies above $40 \mathrm{~Hz}$ [90]. Likewise, it could be safe because the maximum electromagnetic field applicable to fetuses is $800 \mathrm{mv} / \mathrm{m}$ [91], while the electromagnetic field of the rTMS is $100 \mathrm{mv} / \mathrm{m}[92]$.

In terms of treatment effectiveness and safety as well as economic efficiency, rTMS is more attractive method than other treatment methods. When comparing the economic efficiency of antidepressants and rTMS in a study using cohort model, the use of rTMS can save US\$112 dollars for Quality Adjusted Life Years (QALY), which is more cost-effective [93] and In a Singapore study comparing economic efficiency with ECT, the cost of treating rTMS for one year was $\$ 1850$ (US\$8515) cheaper than ECT [94]. rTMS treatment not only leads to neurobiological changes through brain stimulation, but also reduces anxiety about the cost which was one of the risk factor that has the greatest impact on pregnant women [95]. Consequently, socioeconomic costs of peripartum depression could be reduced.

Page $13 / 26$ 
Although the analysis showed high heterogeneity, it is assumed that the parameters that affect the treatment of rTMS are different in each study. In case of publication, funnel plot is asymmetric and $p$-value of Eggar regression is 0.001 . However, except for Garcia's research [62], the funnel plot has a symmetrical structure and has no publication bias with Eggar regression $p$-value $=0.121$. In order to do a more accurate study, high quality clinical trial should be conducted to identify the therapeutic effect of rTMS. How to compensate nontreatment groups is an important consideration. In addition, not only the randomization clinical trials but follow up or cohort study about the children born after treatment should also be conducted. Although many studies considered health of fetus [59, 61, 63-67, 70], only Myczkowski et al [60] considered breastfeeding, and only Eryilmaz et al [88] conducted follow up study of children. One of the main advantages of rTMS is that it has negative effect on the baby. Due to practical constraints, this paper cannot provide a comprehensive review of effect of rTMS on growing babies.

In this study, we have identified 11 studies to collect existing research data and use rTMS to treat peripartum depression and five of them are suitable for quantitative synthesis. According to the analysis of the included studies, rTMS is statistically significant effect on the treatment of PPD and had fewer side effect that were minor. From a variety of perspectives, the treatment of PPD using rTMS can be thought to be an attractive treatment to avoid exposure of chemical ingredients to fetuses and severe side effects of ECT.

\section{Abbreviations}

PPD: Peripartum depression

MDD: Major depressive disorder

ECT: Electroconvulsive therapy

MAO: Monoamine oxidase

rTMS: Repeated transcranial magnetic stimulation

DLPFC: Dorsolateral prefrontal cortex

RCT: Randomized controlled trial

NRS: Non-randomized studies

DSM-5: Diagnostic and Statistical Manual of Mental Disorders-5

HDRS: Hamilton Depression Rating Scale

ROB2: Risk of bias 2

ROBINS-I: The Risk of Bias Assessment tool for Nonrandomized Studies

SMD: Standardized Mean Deviation

MARDS: Montgomery-Åsberg Depression Rating Scale 
BDI: Beck Depression Inventory.

EPDS: Edinburgh Postnatal Depression Scale

QALY: Quality adjusted life year

CGI-S: Clinical Global impression scale

GAS: Global Assessment Scale

SF-36-V: 36-item Quality of Life Health Survey Vitality scores

SF-36-MH: 36-item Quality of Life Health Survey Mental Health scores

\section{Declarations}

\section{Acknowledgements}

We would like to thank Korea Health Industry Development Institute(KHIDI) for supporting

\section{Availability of data and materials}

No data or materials were generated for this narrative review.

\section{Authors' information}

Affiliations

Department of Medical Devices Industry, Dongguk University-Seoul(04620) 30, Pildong-ro 1 -gil, Jung-gu, Seoul, Republic of Korea

Hyune June Lee, Sung Min Kim, Ji Yean Kwon

Contributions

$\mathrm{HJ}$ : Conceive the project, search strategy, screening literature, data extraction, bias evaluation, data analysis, and drafting the manuscript and revising JY: Study design, screening literature, bias evaluation, data analysis, drafting the manuscript, and revising the manuscript and SMK supervised the entire procedures and helped to draft the manuscript. All authors read and approved the final manuscript.

Corresponding author

Correspondence to Ji Yean Kwon(jykwon@dongguk.edu)

\section{Funding}

This research was supported by the training program for advanced medical device industry professional manpower of Korea Health Industry Development Institute (KHIDI) funded by the Ministry of Health and 
Welfare, Republic of Korea.

Ethics approval and consent to participate

Not applicable

Consent for publication

Not applicable

Competing interests

The authors declare that they have no competing interest

\section{References}

1. Association D-AP: Diagnostic and statistical manual of mental disorders. 2013.

2. World Health Organization: Maternal and child mental health https://www.who.int/mental_health/maternal-child/maternal_mental_health/en/. Accessed 20 June 2020.

3. Bauer A, Knapp M, Parsonage M: Lifetime costs of perinatal anxiety and depression. Journal of Affective Disorders 2016, 192:83-90.

4. Schiller CE, Meltzer-Brody S, Rubinow DR: The role of reproductive hormones in postpartum depression. CNS Spectr 2015, 20(1):48-59.

5. Rubio DM, Kraemer KL, Farrell MH, Day NL: Factors associated with alcohol use, depression, and their cooccurrence during pregnancy. Alcohol Clin Exp Res 2008, 32(9):1543-1551.

6. Chang HY, Keyes KM, Lee KS, Choi IA, Kim SJ, Kim KW, Shin YH, Ahn KM, Hong SJ, Shin YJ: Prenatal maternal depression is associated with low birth weight through shorter gestational age in term infants in Korea. Early Hum Dev 2014, 90(1):15-20.

7. Liu C, Cnattingius S, Bergstrom M, Ostberg V, Hjern A: Prenatal parental depression and preterm birth: a national cohort study. BJOG 2016, 123(12):1973-1982.

8. Nylen KJ, O'Hara MW, Engeldinger J: Perceived social support interacts with prenatal depression to predict birth outcomes. J Behav Med 2013, 36(4):427-440.

9. Field T: Prenatal Depression Risk Factors, Developmental Effects and Interventions: A Review. J Pregnancy Child Health 2017, 4(1).

10. Wichman CL, Stern TA: Diagnosing and Treating Depression During Pregnancy. Prim Care Companion CNS Disord 2015, 17(2):10.4088/PCC.4015f01776.

11. Calaway K, Coshal S, Jones K, Coverdale J, Livingston R: A Systematic Review of the Safety of Electroconvulsive Therapy Use During the First Trimester of Pregnancy. J ECT 2016, 32(4):230-235.

12. Eke AC, Saccone G, Berghella V: Selective serotonin reuptake inhibitor (SSRI) use during pregnancy and risk of preterm birth: a systematic review and meta-analysis. BJOG 2016, 123(12):1900-1907. 
13. Leiknes KA, Cooke MJ, Jarosch-von Schweder L, Harboe I, Hoie B: Electroconvulsive therapy during pregnancy: a systematic review of case studies. Arch Womens Ment Health 2015, 18(1):1-39.

14. Prady SL, Hanlon I, Fraser LK, Mikocka-Walus A: A systematic review of maternal antidepressant use in pregnancy and short- and long-term offspring's outcomes. Arch Womens Ment Health 2018, 21(2):127140.

15. Richelson E: Pharmacology of antidepressants. Mayo Clinic Proceedings 2001, 76(5):511-527.

16. Stahl SM: Basic psychopharmacology of antidepressants: Part 1. Antidepressants have seven distinct mechanisms of action. The journal of clinical psychiatry 1998.

17. Hendrick V, Stowe ZN, Altshuler LL, Hwang S, Lee E, Haynes D: Placental passage of antidepressant medications. American Journal of Psychiatry 2003, 160(5):993-996.

18. Nikfar S, Rahimi R, Hendoiee N, Abdollahi M: Increasing the risk of spontaneous abortion and major malformations in newborns following use of serotonin reuptake inhibitors during pregnancy: $\mathrm{A}$ systematic review and updated meta-analysis. Daru : journal of Faculty of Pharmacy, Tehran University of Medical Sciences 2012, 20(1):75-75.

19. Rahimi R, Nikfar S, Abdollahi M: Pregnancy outcomes following exposure to serotonin reuptake inhibitors: a meta-analysis of clinical trials. Reprod Toxicol 2006, 22(4):571-575.

20. Huang H, Coleman S, Bridge JA, Yonkers K, Katon W: A meta-analysis of the relationship between antidepressant use in pregnancy and the risk of preterm birth and low birth weight. Gen Hosp Psychiatry 2014, 36(1):13-18.

21. Julsgaard M, Christensen LA, Gibson PR, Gearry RB, Fallingborg J, Hvas CL, Bibby BM, Uldbjerg N, Connell WR, Rosella $\mathrm{O}$ et al: Concentrations of Adalimumab and Infliximab in Mothers and Newborns, and Effects on Infection. Gastroenterology 2016, 151(1):110-119.

22. Boukhris T, Sheehy O, Mottron L, Berard A: Antidepressant Use During Pregnancy and the Risk of Autism Spectrum Disorder in Children. JAMA Pediatr 2016, 170(2):117-124.

23. Brown AS, Gyllenberg D, Malm H, McKeague IW, Hinkka-Yli-Salomaki S, Artama M, Gissler M, CheslackPostava K, Weissman MM, Gingrich JA et al: Association of Selective Serotonin Reuptake Inhibitor Exposure During Pregnancy With Speech, Scholastic, and Motor Disorders in Offspring. JAMA Psychiatry 2016, 73(11):1163-1170.

24. Huybrechts KF, Palmsten K, Avorn J, Cohen LS, Holmes LB, Franklin JM, Mogun H, Levin R, Kowal M, Setoguchi S et al: Antidepressant Use in Pregnancy and the Risk of Cardiac Defects. Obstetric Anesthesia Digest 2015, 35(2).

25. Huybrechts KF, Bateman BT, Palmsten K, Desai RJ, Patorno E, Gopalakrishnan C, Levin R, Mogun H, Hernandez-Diaz S: Antidepressant use late in pregnancy and risk of persistent pulmonary hypertension of the newborn. JAMA 2015, 313(21):2142-2151.

26. Berle JØ, Spigset O: Antidepressant Use During Breastfeeding. Curr Womens Health Rev 2011, 7(1):28-34.

27. Davanzo R, Copertino M, De Cunto A, Minen F, Amaddeo A: Antidepressant drugs and breastfeeding: a review of the literature. Breastfeeding medicine 2011, 6(2):89-98.

28. Schmidt K, Olesen OV, Jensen PN: Citalopram and breast-feeding: serum concentration and side effects in the infant. Biological Psychiatry 2000, 47(2):164-165. 
29. Lee A, Woo J, Ito S: Frequency of infant adverse events that are associated with citalopram use during breast-feeding. American Journal of Obstetrics and Gynecology 2004, 190(1):218-221.

30. Singh A, Kar SK: How Electroconvulsive Therapy Works?: Understanding the Neurobiological Mechanisms. Clin Psychopharmacol Neurosci 2017, 15(3):210-221.

31. Balki M, Castro C, Ananthanarayan C: Status epilepticus after electroconvulsive therapy in a pregnant patient. International Journal of Obstetric Anesthesia 2006, 15(4):325-328.

32. Pesiridou A, Baquero G, Cristancho P, Wakil L, Altinay M, Kim D, O'Reardon JP: A case of delayed onset of threatened premature labor in association with electroconvulsive therapy in the third trimester of pregnancy. J ECT 2010, 26(3):228-230.

33. Bozkurt A KT, Isintas M, Ozmenler NK, Ozsahin A, Yanarates O: Acute and maintenance electroconvulsive therapy for treatment of psychotic depression in a pregnant patient.J ECT 2007, 23(3):185-187.

34. Lovas A, Almos PZ, Peto Z, Must A, Horvath S: Anesthesia for electroconvulsive therapy in early pregnancy. J ECT 2011, 27(4):328-330.

35. Koren G, Nordeng H: Antidepressant use during pregnancy: the benefit-risk ratio. American journal of obstetrics and gynecology 2012, 207(3):157-163.

36. Saatcioglu 0, Tomruk NB: The use of electroconvulsive therapy in pregnancy: a review. The Israel journal of psychiatry and related sciences 2011, 48(1):6.

37. Health Quality O: Repetitive Transcranial Magnetic Stimulation for Treatment-Resistant Depression: A Systematic Review and Meta-Analysis of Randomized Controlled Trials. Ont Health Technol Assess Ser 2016, 16(5):1-66.

38. George MS, Taylor JJ, Short EB: The expanding evidence base for rTMS treatment of depression. Curr Opin Psychiatry 2013, 26(1):13-18.

39. Voigt J, Carpenter L, Leuchter A: A systematic literature review of the clinical efficacy of repetitive transcranial magnetic stimulation (rTMS) in non-treatment resistant patients with major depressive disorder. BMC psychiatry 2019, 19(1):13.

40. McNamara B, Ray J, Arthurs O, Boniface S: Transcranial magnetic stimulation for depression and other psychiatric disorders. Psychological medicine 2001, 31(7):1141-1146.

41. KOZEL FA, GEORGE MS: Meta-analysis of left prefrontal repetitive transcranial magnetic stimulation (rTMS) to treat depression. Journal of Psychiatric Practice ${ }^{\circledR}$ 2002, 8(5):270-275.

42. Burt T, Lisanby SH, Sackeim HA: Neuropsychiatric applications of transcranial magnetic stimulation: a meta analysis. International Journal of Neuropsychopharmacology 2002, 5(1):73-103.

43. VanDerwerker CJ, Ross RE, Stimpson KH, Embry AE, Aaron SE, Cence B, George MS, Gregory CM: Combining therapeutic approaches: rTMS and aerobic exercise in post-stroke depression: a case series. Top Stroke Rehabil 2018, 25(1):61-67.

44. Krepel N, Rush AJ, Iseger TA, Sack AT, Arns M: Can psychological features predict antidepressant response to rTMS? A Discovery-Replication approach. Psychol Med 2017, 50(2):264-272.

45. Chang D, Zhang J, Peng W, Shen Z, Gao X, Du Y, Ge Q, Song D, Shang Y, Wang Z: Smoking Cessation With $20 \mathrm{~Hz}$ Repetitive Transcranial Magnetic Stimulation (rTMS) Applied to Two Brain Regions: A Pilot Study. Front Hum Neurosci 2018, 12:344. 
46. Konstantinou GN, Vigod SN, Mehta S, Daskalakis ZJ, Blumberger DM: "A systematic review of noninvasive neurostimulation for the treatment of depression during pregnancy". Journal of Affective Disorders 2020, 272:259-268.

47. Ganho-Ávila A, Poleszczyk A, Mohamed MMA, Osório A: Efficacy of rTMS in decreasing postnatal depression symptoms: A systematic review. Psychiatry Res 2019, 279:315-322.

48. Felipe RdM, Ferrão YA: Transcranial magnetic stimulation for treatment of major depression during pregnancy: a review. Trends in Psychiatry and Psychotherapy 2016, 38:190-197.

49. Cole J, Bright K, Gagnon L, McGirr A: A systematic review of the safety and effectiveness of repetitive transcranial magnetic stimulation in the treatment of peripartum depression. Journal of Psychiatric Research 2019, 115:142-150.

50. Woody CA, Ferrari AJ, Siskind DJ, Whiteford HA, Harris MG: A systematic review and meta-regression of the prevalence and incidence of perinatal depression. $J$ Affect Disord 2017, 219:86-92.

51. Wisner KL, Sit DK, McShea MC, Rizzo DM, Zoretich RA, Hughes CL, Eng HF, Luther JF, Wisniewski SR, Costantino $\mathrm{ML}$ et al: Onset timing, thoughts of self-harm, and diagnoses in postpartum women with screen-positive depression findings. JAMA Psychiatry 2013, 70(5):490-498.

52. Stuart-Parrigon K, Stuart S: Perinatal depression: an update and overview. Curr Psychiatry Rep 2014, 16(9):468.

53. Akl E, Altman D, Aluko P, Askie L, Beaton D, Berlin J, Bhaumik B, Bingham C, Boers M, Booth A et al: Cochrane Handbook for Systematic Reviews of Interventions; 2019.

54. Spronk D, Arns M, Fitzgerald PB: Repetitive transcranial magnetic stimulation in depression: protocols, mechanisms, and new developments. In: Neurofeedback and Neuromodulation Techniques and Applications. edn.: Elsevier; 2011: 257-291.

55. Sterne JA, Savović J, Page MJ, Elbers RG, Blencowe NS, Boutron I, Cates CJ, Cheng H-Y, Corbett MS, Eldridge SM: RoB 2: a revised tool for assessing risk of bias in randomised trials. BMJ 2019, 366.

56. Sterne JA, Hernán MA, Reeves BC, Savović J, Berkman ND, Viswanathan M, Henry D, Altman DG, Ansari MT, Boutron I: ROBINS-I: a tool for assessing risk of bias in non-randomised studies of interventions. $B M J$ $2016,355$.

57. Carey JC: Significance of case reports in the advancement of medical scientific knowledge. Am J Med Genet A 2006, 140(19):2131-2134.

58. Murad MH, Sultan S, Haffar S, Bazerbachi F: Methodological quality and synthesis of case series and case reports. BMJ Evid Based Med 2018, 23(2):60-63.

59. Kim DR, Wang E, McGeehan B, Snell J, Ewing G, lannelli C, O'Reardon JP, Sammel MD, Epperson CN: Randomized controlled trial of transcranial magnetic stimulation in pregnant women with major depressive disorder. Brain Stimul 2019, 12(1):96-102.

60. Myczkowski ML, Dias AM, Luvisotto T, Arnaut D, Bellini BB, Mansur CG, Renno J, Tortella G, Ribeiro PL, Marcolin MA: Effects of repetitive transcranial magnetic stimulation on clinical, social, and cognitive performance in postpartum depression. Neuropsychiatr Dis Treat 2012, 8:491-500.

61. Kim DR, Epperson N, Pare E, Gonzalez JM, Parry S, Thase ME, Cristancho P, Sammel MD, O'Reardon JP: An open label pilot study of transcranial magnetic stimulation for pregnant women with major depressive 
disorder. J Womens Health (Larchmt) 2011, 20(2):255-261.

62. Garcia KS, Flynn P, Pierce KJ, Caudle M: Repetitive transcranial magnetic stimulation treats postpartum depression. Brain Stimul 2010, 3(1):36-41.

63. Hizli Sayar G, Ozten E, Tufan E, Cerit C, Kagan G, Dilbaz N, Tarhan N: Transcranial magnetic stimulation during pregnancy. Arch Womens Ment Health 2014, 17(4):311-315.

64. Tan O, Tarhan N, Coban A, Baripoglu SK, Guducu F, Izgi HB, Hizli G, Ates O, Bulut H: Antidepressant Effect of 58 Sessions of rTMS in a Pregnant Woman With Recurrent Major Depressive Disorder: A Case Report. Prim Care Companion J Clin Psychiatry 2008, 10(1):69-71.

65. Zhang X, Liu K, Sun J, Zheng Z: Safety and feasibility of repetitive transcranial magnetic stimulation (rTMS) as a treatment for major depression during pregnancy. Arch Womens Ment Health 2010, 13(4):369-370.

66. Ferra o YA, Silva RdMFd: Repetitive transcranial magnetic stimulation for the treatment of major depression during pregnancy. Braz J Psychiatry 2018, 40(1):227-228.

67. Cohen RB, Ferreira MS, Ferreira MJ, Fregni F: Use of repetitive transcranial magnetic stimulation for the management of bipolar disorder during the postpartum period. Brain Stimulation: Basic, Translational, and Clinical Research in Neuromodulation 2008, 1(3):224-226.

68. Klírová M, Novak T, Kopecek M, Mohr P, Strunzova V: Repetitive transcranial magnetic stimulation (rTMS) in major depressive episode during pregnancy. Neuro endocrinology letters 2008, 29:69-70.

69. Burton C, Gill S, Clarke P, Galletly C: Maintaining remission of depression with repetitive transcranial magnetic stimulation during pregnancy: a case report. Arch Womens Ment Health 2014, 17(3):247-250.

70. Tarhan N, Sayar FG, Tan O, Kagan G: Efficacy of high-frequency repetitive transcranial magnetic stimulation in treatment-resistant depression. Clin EEG Neurosci 2012, 43(4):279-284.

71. Becker BJ: Synthesizing standardized mean-change measures. British Journal of Mathematical and Statistical Psychology 1988, 41(2):257-278.

72. Higgins JPT, Thompson SG, Deeks JJ, Altman DG: Measuring inconsistency in meta-analyses. BMJ 2003, 327(7414):557-560.

73. Cohen J: Statistical power analysis for the behavioral sciences: Academic press; 2013.

74. O'Mahen HA, Flynn HA: Preferences and perceived barriers to treatment for depression during the perinatal period. Journal of women's health 2008, 17(8):1301-1309.

75. Goodman JH: Women's attitudes, preferences, and perceived barriers to treatment for perinatal depression. Birth 2009, 36(1):60-69.

76. Maughan D, Molodynski A: An international perspective on the acceptability and sustainability of electroconvulsive therapy. BJPsych Int 2016, 13(1):10-12.

77. Kim DR, Sockol L, Barber JP, Moseley M, Lamprou L, Rickels K, O'Reardon JP, Epperson CN: A survey of patient acceptability of repetitive transcranial magnetic stimulation (TMS) during pregnancy. Journal of affective disorders 2011, 129(1-3):385-390.

78. Nahas Z, Bohning D, Molloy A, Oustz JA, Risch S, George M: Safety and Feasibility of Repetitive Transcranial Magnetic Stimulation in the Treatment of Anxious Depression in Pregnancy. The Journal of clinical psychiatry 1999, 60:50-52. 
79. Ozmut O, Balibey H, Yilan Y, Algul A, Ebrinc S, Cetin M, Tutuncu R, Ates A, Basoglu C: Repetitive transcranial magnetic stimulation for the treatment of depression during pregnancy and postpartum period. Bulletin of Clinical Psychopharmacology 2015, 25(1):S203-S204.

80. Brock DG, Demitrack MA, Groom P, Holbert R, Rado JT, Gross PK, Goethe JW, Schrodt GR, Weeks HR: Effectiveness of NeuroStar transcranial magnetic stimulation (TMS) in patients with major depressive disorder with postpartum onset. Brain Stimulation 2016, 9(5).

81. Stultz DJ, Thistlethwaite D, Voltin R, Osburn S, Walton R, Burns T: Bipolar, depressed, and pregnant transcranial magnetic stimulation as a treatment alternative. Brain Stimulation 2018, 11(6).

82. Xiong W, Lopez R, Cristancho P: Transcranial magnetic stimulation in the treatment of peripartum bipolar depression: a case report. Braz J Psychiatry 2018, 40(3):344-345.

83. Kim DR, Wang E: Prevention of supine hypotensive syndrome in pregnant women treated with transcranial magnetic stimulation. Psychiatry Res 2014, 218(1-2):247-248.

84. Fitelson E, Kim S, Baker AS, Leight K: Treatment of postpartum depression: clinical, psychological and pharmacological options. International journal of women's health 2011, 3:1.

85. Payne JL, Meltzer-Brody S: Antidepressant use during pregnancy: current controversies and treatment strategies. Clin Obstet Gynecol 2009, 52(3):469-482.

86. Cepeda MS, Kern DM, Nicholson S: Treatment resistant depression in women with peripartum depression. BMC Pregnancy and Childbirth 2019, 19(1):323.

87. Blencowe H, Cousens S, Oestergaard MZ, Chou D, Moller A-B, Narwal R, Adler A, Vera Garcia C, Rohde S, Say $L$ et al: National, regional, and worldwide estimates of preterm birth rates in the year 2010 with time trends since 1990 for selected countries: a systematic analysis and implications. The Lancet 2012, 379(9832):2162-2172.

88. Eryilmaz G, Sayar GH, Ozten E, Gul IG, Yorbik O, Isiten N, Bagci E: Follow-up study of children whose mothers were treated with transcranial magnetic stimulation during pregnancy: preliminary results. Neuromodulation 2015, 18(4):255-260.

89. Bracken MB, Belanger K, Cookson WO, Triche E, Christiani DC, Leaderer BP: Genetic and Perinatal Risk Factors for Asthma Onset and Severity: A Review and Theoretical Analysis. Epidemiologic Reviews 2002, 24(2):176-189.

90. Li D-K, Chen H, Odouli R: Maternal Exposure to Magnetic Fields During Pregnancy in Relation to the Risk of Asthma in Offspring. Archives of Pediatrics \& Adolescent Medicine 2011, 165(10):945-950.

91. Allen CH, Kluger BM, Buard I: Safety of Transcranial Magnetic Stimulation in Children: A Systematic Review of the Literature. Pediatr Neurol 2017, 68:3-17.

92. Yanamadala J, Noetscher GM, Makarov SN, Pascual-Leone A: Estimates of peak electric fields induced by Transcranial magnetic stimulation in pregnant women as patients using an FEM full-body model. In: 2017 39th Annual International Conference of the IEEE Engineering in Medicine and Biology Society (EMBC): 11-15 July 2017 2017; 2017: 1441-1444.

93. Simpson KN, Welch MJ, Kozel FA, Demitrack MA, Nahas Z: Cost-effectiveness of transcranial magnetic stimulation in the treatment of major depression: a health economics analysis. Advances in therapy 2009, 26(3):346-368. 
94. Zhao YJ, Tor PC, Khoo AL, Teng M, Lim BP, Mok YM: Cost-Effectiveness Modeling of Repetitive Transcranial Magnetic Stimulation Compared to Electroconvulsive Therapy for Treatment-Resistant Depression in Singapore. Neuromodulation: Technology at the Neural Interface 2018, 21(4):376-382.

95. Lancaster CA, Gold KJ, Flynn HA, Yoo H, Marcus SM, Davis MM: Risk factors for depressive symptoms during pregnancy: a systematic review. American journal of obstetrics and gynecology 2010, 202(1):5-14.

\section{Figures}

Basic information

- Title of the paper, author, year of publication.

Study Characteristics

- Study design, number of subjects, dropout rate, bias risk assessment factor

Subjects Characteristics

- Age, primary psychiatric diagnosis, gestational age, and simultaneous treatment

Treatment Characteristics

- Motor threshold, site of stimulation, frequency and pulse, interval time, number of sessions

\section{Result Characteristics}

- Treatment effect for the mothers, side effects on mothers, side effects on fetuses,

\section{Figure 1}

Data extraction items. 


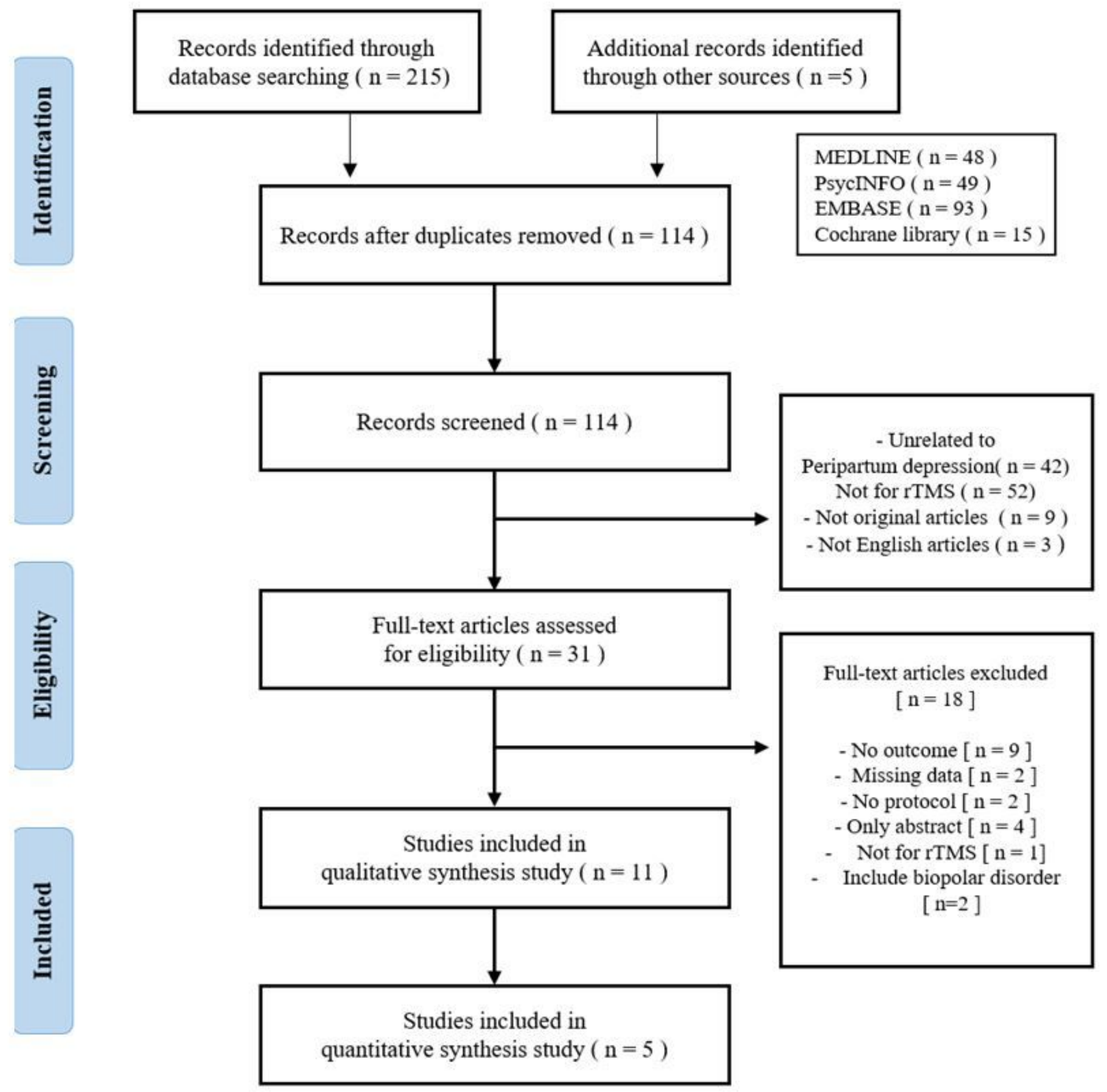

Figure 2

Study Selection PRISMA flow diagram. 
Study name

\begin{tabular}{|c|c|c|c|c|c|c|c|c|}
\hline & & $\begin{array}{c}\text { Std diff } \\
\text { in means }\end{array}$ & $\begin{array}{c}\text { Standard } \\
\text { error }\end{array}$ & Variance & $\begin{array}{c}\text { Lower } \\
\text { limit }\end{array}$ & $\begin{array}{l}\text { Upper } \\
\text { limit }\end{array}$ & Z-Value & $\mathrm{p}-\mathrm{Va}$ \\
\hline D. R. Kim et al., 2019 & BAI & 0.260 & 0.428 & 0.183 & -0.579 & 1.100 & 0.608 & .543 \\
\hline D. R. Kim et al., 2019 & $B D I$ & 1.399 & 0.476 & 0.226 & 0.467 & 2.332 & 2.942 & .003 \\
\hline D. R. Kim et al., 2019 & CGLS & 0.366 & 0.430 & 0.185 & -0.477 & 1.209 & 0.851 & .35 \\
\hline D. R. Kim et at., 2019 & EPDS & 0.463 & 0.432 & 0.187 & -0.383 & 1.310 & 1.073 & 28 \\
\hline D. R. Kim et al., 2019 & HDRS-17 & 0.680 & 0.439 & 0.192 & -0.180 & 1.539 & 1.550 & 12 \\
\hline Myczkowski et al., 2012 & 2 CGLS & 1.225 & 0.588 & 0.345 & 0.073 & 2.376 & 2.084 & 0.037 \\
\hline Myczkowski et al., 2012 & 2 EPDS & 0.995 & 0.572 & 0.327 & -0.126 & 2.116 & 1.740 & 0.082 \\
\hline Myczkowski et al., 2012 & 2 GAS & 0.839 & 0.563 & 0.317 & -0.264 & 1.942 & 1.490 & 138 \\
\hline Myczkowski et al., 2012 & 2 HARS- 14 & 0.733 & 0.558 & 0.311 & -0.359 & 1.826 & 1.315 & 18 \\
\hline Myczkowski et al., 2012 & 2 HDRS- 17 & 0.980 & 0.571 & 0.326 & -0.139 & 2.099 & 1.717 & .08 \\
\hline Myczkowski et al., 2012 & $2 \mathrm{SF}-36-\mathrm{MH}$ & 0.968 & 0.570 & 0.325 & -0.149 & 2.086 & 1.698 & 0.08 \\
\hline Myczkowski et al, 2012 & $2 \mathrm{SF}-36-\mathrm{V}$ & 0.826 & 0.562 & 0.316 & -0.276 & 1.928 & 1.469 & 0.142 \\
\hline D. R. Kim et al., 2011 & BAI & 0.284 & 0.323 & 0.104 & -0.348 & 0.917 & 0.882 & 0.37 \\
\hline D. R. Kim et al., 2011 & $B D I$ & 1.429 & 0.450 & 0.202 & 0.548 & 2.310 & 3.178 & 0.00 \\
\hline D. R. Kim et al., 2011 & CGISS & 4.644 & 1.085 & 1.178 & 2.516 & 6.771 & 4.278 & 0.000 \\
\hline D. R. Kim et al., 2011 & HDRS- 17 & 2.506 & 0.643 & 0.414 & 1.245 & 3.767 & 3.895 & $0.00 \mathrm{c}$ \\
\hline Hizli Sayar et al., 2011 & HDRS & 2.159 & 0.339 & 0.115 & 1.495 & 2.824 & 6.371 & 0.000 \\
\hline Garcia et al., 2010 & CGLS & 7.526 & 2.047 & 4.189 & 3.515 & 11.538 & 3.677 & 0.000 \\
\hline Garcia et al., 2010 & EPDS & 3.585 & 1.030 & 1.061 & 1.566 & 5.603 & 3.481 & 0.00 \\
\hline Garcia et al., 2010 & HDRS-24 & 4.095 & 1.158 & 1.340 & 1.825 & 6.364 & 3.537 & 0.00 \\
\hline Garcia et al., 2010 & IDS-SR & 3.409 & 0.986 & 0.973 & 1.476 & 5.342 & 3.456 & 0.0 \\
\hline
\end{tabular}

Std diff in means and $95 \% \mathrm{Cl}$

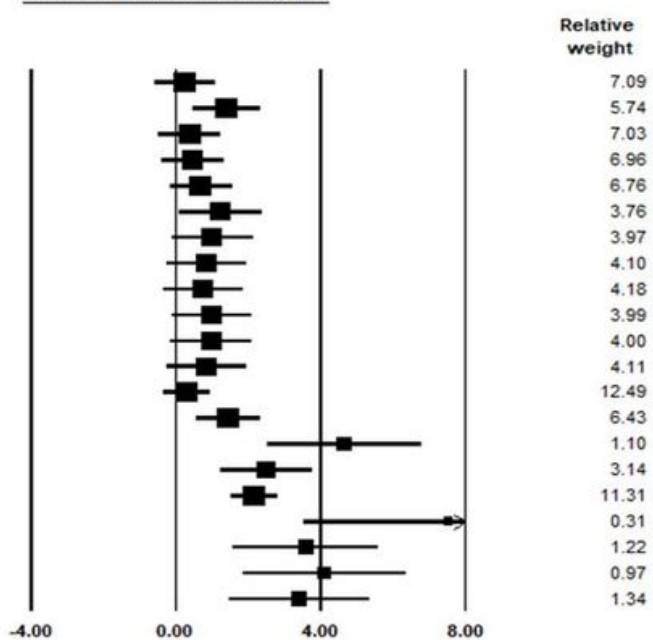

\begin{tabular}{|c|c|c|c|c|c|c|c|c|c|c|c|c|c|c|c|c|}
\hline \multicolumn{2}{|l|}{ Model } & \multicolumn{5}{|c|}{ Effect size and $95 \%$ confidence interval } & \multicolumn{3}{|c|}{ Test of null [2-Tail] } & \multicolumn{4}{|c|}{ Heterogeneity } & \multicolumn{3}{|c|}{ Tau-squared } \\
\hline Model & $\begin{array}{l}\text { Number } \\
\text { Studies }\end{array}$ & $\begin{array}{l}\text { Point } \\
\text { estimate }\end{array}$ & $\begin{array}{c}\text { Standard } \\
\text { entor }\end{array}$ & Variance & $\begin{array}{l}\text { Lower } \\
\text { limit }\end{array}$ & $\begin{array}{l}\text { Upper } \\
\text { limit }\end{array}$ & Z-value & P-value & Q-value & $d f(Q)$ & P-value & 1-squared & $\begin{array}{c}\text { Tau } \\
\text { Squared }\end{array}$ & $\begin{array}{c}\text { Standard } \\
\text { Error }\end{array}$ & Variance & Tau \\
\hline Foxed & 21 & 1.119 & 0.114 & 0.013 & 0.896 & 1.343 & 9.818 & 0,000 & 71.258 & 20 & 0.000 & 71.933 & 0.715 & 0.346 & 0.120 & 0.845 \\
\hline Random & 21 & 1.394 & 0.229 & 0.053 & 0.944 & 1.843 & 6.079 & 0,000 & & & & & & & & \\
\hline
\end{tabular}

Figure 3

Forest plot of therapeutic effect. Abbreviations: BAl: Beck Anxiety Inventory; BDI: Beck depression Inventory; CGI-S: Clinical Global impression scale; EPDS: Edinburgh Postnatal Depression Scale; HDRS: Hamilton Depression Rating Scale; GAS, Global Assessment Scale; SF-36-V and SF-36-MH: 36-item Quality of Life Health Survey, Vitality and Mental Health scores; IDS-SR: Inventory of Depressive Symptomatology-SelfReport.

Study name

D. R. Kim et al., 2019

Myczkowski et al., 2012

D. R. Kim et al., 2011

Hizli Sayar et al., 2014

Garcia et al., 2010
Statistics for each study

\section{Event Lower Upper}

rate limit limit $Z$-Value $p$-Value

$\begin{array}{lllrl}0.364 & 0.143 & 0.661 & -0.893 & 0.372 \\ 0.250 & 0.063 & 0.623 & -1.346 & 0.178 \\ 0.500 & 0.225 & 0.775 & 0.000 & 1.000 \\ 0.016 & 0.001 & 0.211 & -2.883 & 0.004 \\ 0.429 & 0.144 & 0.770 & -0.377 & 0.706 \\ 0.346 & 0.214 & 0.506 & -1.889 & 0.059\end{array}$

0.143

0.661

0.059
Event rate and $95 \% \mathrm{Cl}$

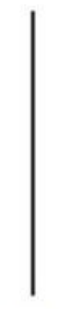

$-1.00$

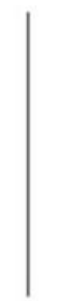

$-0.50$

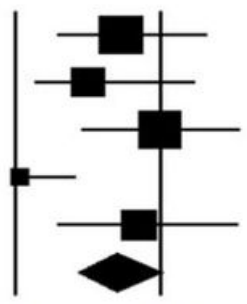

0.50

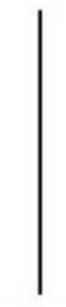

1.00

\begin{tabular}{|c|c|c|c|c|c|c|c|c|c|c|c|c|c|c|}
\hline \multicolumn{2}{|l|}{ Model } & \multicolumn{3}{|c|}{ Effect size and $95 \%$ interval } & \multicolumn{3}{|c|}{ Test of null [2-Tail) } & \multicolumn{4}{|c|}{ Heterogeneity } & \multicolumn{3}{|c|}{ Tau-squared } \\
\hline Model & $\begin{array}{l}\text { Number } \\
\text { Studies }\end{array}$ & $\begin{array}{c}\text { Point } \\
\text { estimate }\end{array}$ & $\begin{array}{c}\text { Lower } \\
\text { limit }\end{array}$ & $\begin{array}{c}\text { Upper } \\
\text { limit }\end{array}$ & $Z$-value & P-value & Q-value & df $[Q]$ & P-value & I-squared & $\begin{array}{c}\text { Tau } \\
\text { Squared }\end{array}$ & $\begin{array}{l}\text { Standard } \\
\text { Errot }\end{array}$ & Variance & Tau \\
\hline Fived & 5 & 0.346 & 0.214 & 0.506 & -1.889 & 0.059 & 7.495 & 4 & 0.112 & 46.631 & 0.523 & 0.809 & 0.655 & 0.724 \\
\hline Random & 5 & 0.312 & 0.150 & 0.539 & -1.639 & 0.101 & & & & & & & & \\
\hline
\end{tabular}

Figure 4

Forest plot of side effect. 


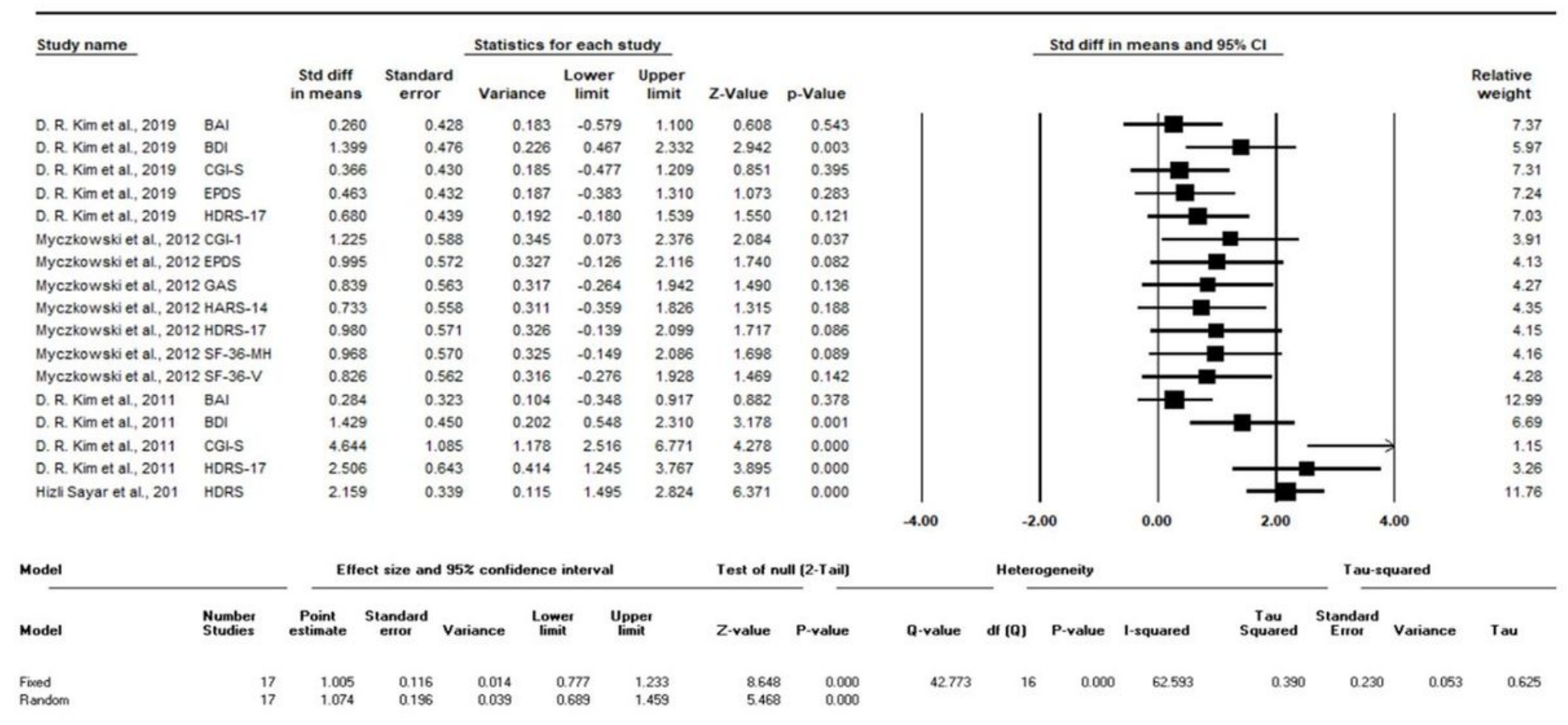

Figure 5

Forest plot of therapeutic effect without Garcia study. Abbreviations: BAl: Beck Anxiety Inventory; BDI: Beck depression Inventory; CGI-S: Clinical Global impression scale; EPDS: Edinburgh Postnatal Depression Scale; HDRS: Hamilton Depression Rating Scale; GAS, Global Assessment Scale; SF-36-V and SF-36-MH: 36-item Quality of Life Health Survey, Vitality and Mental Health scores.

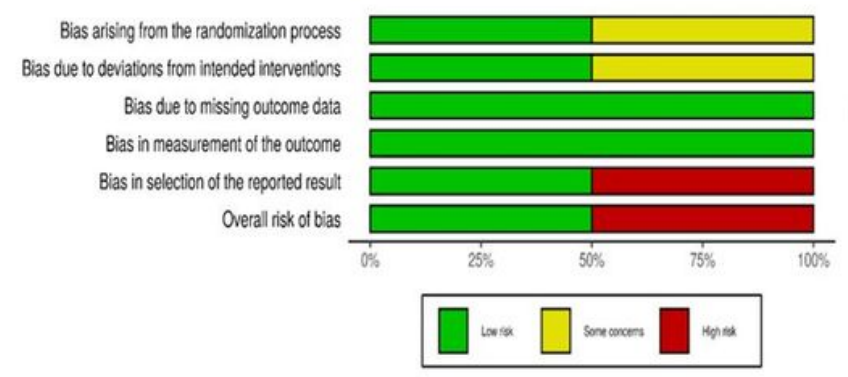

(A) RCT risk of bias

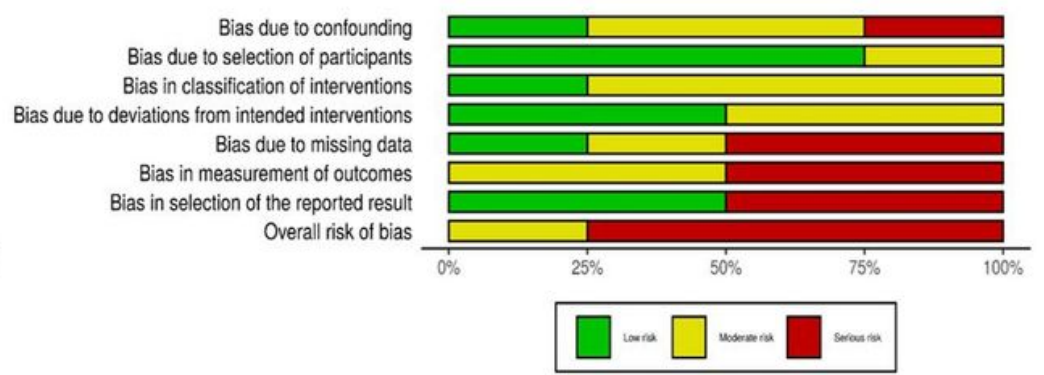

(B) NRS risk of bias

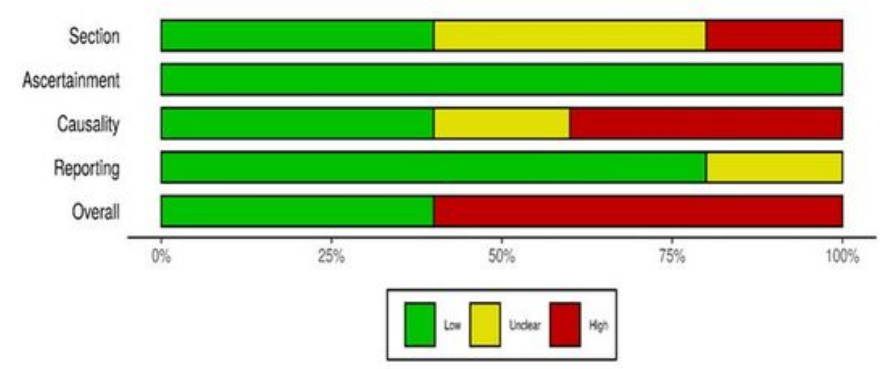

(C) Case study risk of bias

\section{Figure 6}

Risk of bias graph. (A) RCT risk of bias graph; (B) NRS risk of bias graph; (C) case study risk of bias graph. 
Funnel Plot of Standard Error by Std diff in means

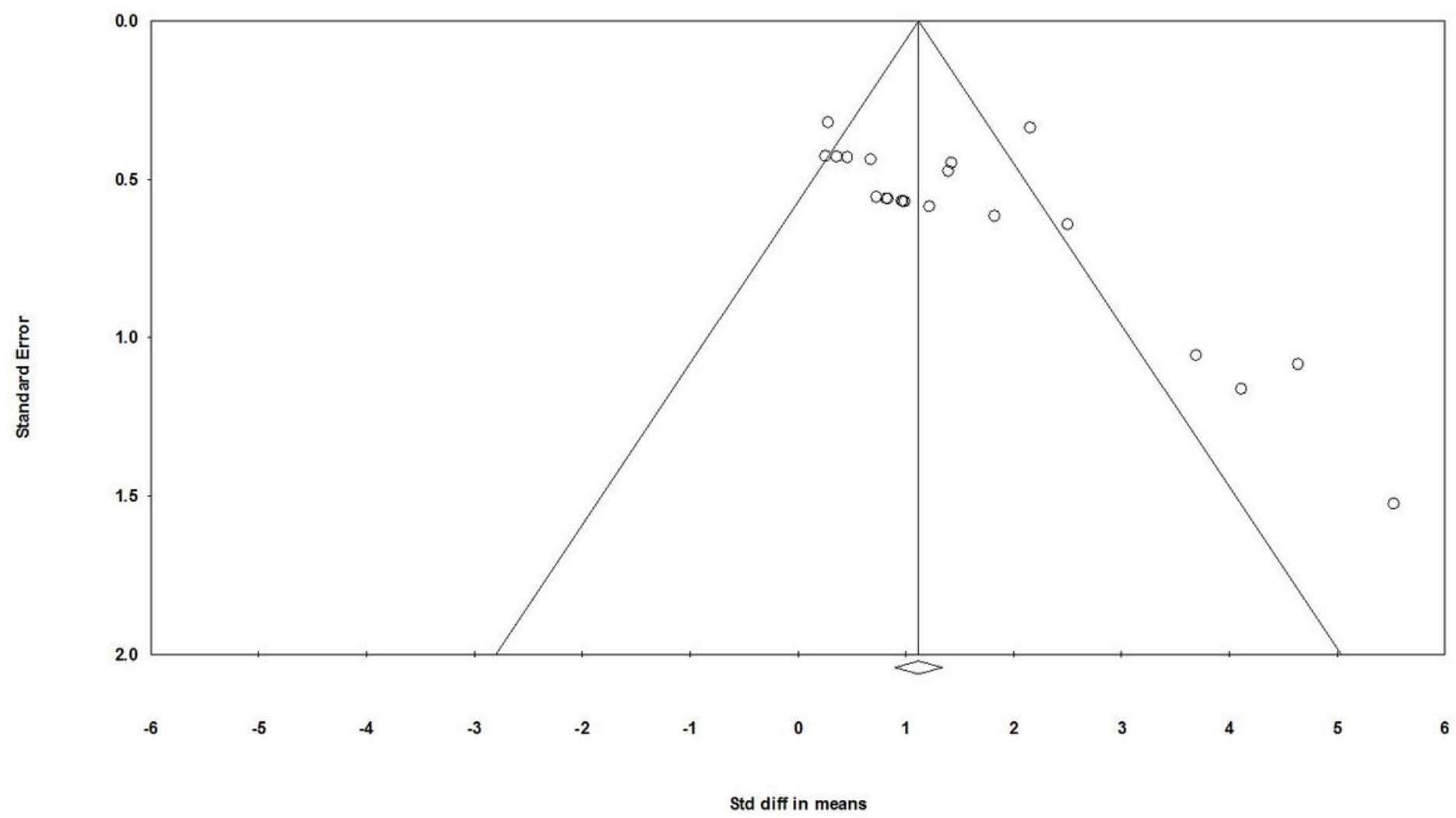

Figure 7

Funnel plot of rTMS effect for PPD.

\section{Supplementary Files}

This is a list of supplementary files associated with this preprint. Click to download.

- Appendix4PRISMAchecklist.doc

- Appendix3Riskofbiasassessment.docx

- Appendix2Excludedstudies.docx

- Appendix1Searchingstrategy.docx 